\title{
High-Temperature Characterization of Alumina Substrates and Folded Slot Antenna
}

\author{
Maximilian C. Scardelletti, Jennifer L. Jordan ", Amy R. Stalker, \\ and George E. Ponchak \\ NASA Glenn Research Center, Cleveland, Ohio, 44135 \\ Maximilian.C.Scardelletti@nasa.gov
}

\begin{abstract}
The characterization of $99.6 \%$ polycrystalline alumina substrates and folded slot antennas is presented in this paper. Coplanar Waveguide (CPW) calibration standards where fabricated on $99.6 \%$ polycrystalline alumina substrates. Thru-Reflect-Line (TRL) calibrations were performed at temperatures of 25 to $400^{\circ} \mathrm{C}$ over a frequency range from 0.5 to $50 \mathrm{GHz}$. The effective dielectric constant of the alumina substrates was determined to be relatively constant at 5.4 from 25 to $200^{\circ} \mathrm{C}$ and then increased steadily to approximately 6 at $400^{\circ} \mathrm{C}$. The loss of the $\mathrm{CPW}$ lines increased as temperature and frequency increased as well noting that the increase in loss is even more profound as both the temperature and frequency increased simultaneously.
\end{abstract}

A CPW fed folded slot antenna fabricated on the alumina substrates is also presented. The Return Loss (RL) of a CPW fed folded slot antenna exhibits a self impedance matching technique. The RL of the folded slot antenna at $25^{\circ} \mathrm{C}$ displays a resonance at $3.5 \mathrm{GHz}$ and is approximately $16 \mathrm{~dB}$ in magnitude. At $300^{\circ} \mathrm{C}$ the resonance shifts down in frequency to approximately $3.3 \mathrm{~dB}$ and has roughly the same magnitude. However the loss of the antenna response also increases at this elevated temperature.

This work is part of the initial stages of an effort at NASA Glenn research Center to develop wireless sensors for harsh environments. This work can reduce cost, space to house all the hard wired connections, and reduce the weight of the overall units such as aerospace engines and allow for the placement of the wireless sensors in the engine which are not possible with hard wired sensors. 


\title{
High Temperature Characterization of Alumina Substrates and Folded Slot Antenna
}

\author{
Maximilian C. Scardelletti, Jennifer L. Jordan", Amy R. Stalker, \\ and George E. Ponchak \\ NASA Glenn Research Center, Cleveland, Ohio, 44135 \\ Maximilian.C.Scardelletti@nasa.gov
}

\section{Introduction}

The ability to use high temperature electronics in wireless sensing applications is of great interest. Wireless sensors that can be used in harsh environments to transmit critical data back to a diagnostic counterpart can alleviate hard wire connections and other electronics otherwise required to complete the data path. For example the ability to characterize in-situ combustion environments of aerospace engines via wireless sensors would reduce the weight and space required to position the wire as well as allowing the opportunity to position the sensors in areas of the engine that were previously not possible when only hard wire connection is available.

Antenna characterization at elevated temperatures is required for the development of wireless electronics that operate in harsh environments, such as in aircraft engines. This paper discusses the characterization of $99.6 \%$ polycrystalline $\mathrm{Al}_{2} \mathrm{O}_{3}$ (alumina) substrates from $25^{\circ} \mathrm{C}$ to $400^{\circ} \mathrm{C}$ over a frequency range from $0.5 \mathrm{GHz}$ to $50 \mathrm{GHz}$. A coplanar waveguide (CPW) fed folded slot antenna fabricated on the alumina substrate is characterized over the temperature range.

\section{Alumina Characterization}

To characterize the properties of the alumina substrates at elevated temperatures, CPW Thru-Reflect-Line (TRL) calibration standards were developed [1]. The CPW standards have a center conductor width of $130 \mu \mathrm{m}$ and slot widths of 60 $\mu \mathrm{m}$ consisting of chrome $(\mathrm{Cr})$ and gold $(\mathrm{Au})$ with thicknesses of $200 \AA$ and 1.5 $\mu \mathrm{m}$, respectively. The thru line is $5000 \mu \mathrm{m}$ long, the short is $2500 \mu \mathrm{m}$ long, and 4 delay lines of $15000,6000,2950,844 \mu \mathrm{m}$ long, not including the $5000 \mu \mathrm{m}$ length for the thru line, are used. The substrate is $99.6 \%$ polycrystalline alumina with a thickness of $635 \mu \mathrm{m}$. The calibration was performed using Multical calibration software by NIST [2] and the HP 8510 C VNA at 25, 50, 100, 150, 200, 250, 300, 350 , and $400^{\circ} \mathrm{C}$. To heat the calibration standards on the alumina substrates, a special probe station with modified ground-signal-ground (GSG) probes was constructed [3]. For each temperature, Multical calculated the effective permittivity and attenuation of the CPW line. Figure 1a illustrates the effective dielectric constant vs. temperature at 5 and $10 \mathrm{GHz}$. The effective dielectric constant gradually increases from 5.4 to 6 , which is an increase of approximately $10 \%$, as the temperature rises from room temperature $\left(25^{\circ} \mathrm{C}\right)$ to $400^{\circ} \mathrm{C}$. 
The attenuation vs. temperature at $10 \mathrm{GHz}$ and $20 \mathrm{GHz}$ is shown in Figure $1 \mathrm{~b}$. The loss is approximately $0.5 \mathrm{~dB} / \mathrm{cm}$ until the temperature reaches $200^{\circ} \mathrm{C}$, after which it begins to rise steadily as the temperature increases to $400^{\circ} \mathrm{C}$. At $400^{\circ} \mathrm{C}$, the loss is 3 and $3.5 \mathrm{~dB} / \mathrm{cm}$ at 10 and $20 \mathrm{GHz}$, respectively. Figure 2 shows the attenuation of the CPW transmission lines over a frequency band from 0.5 to 50 $\mathrm{GHz}$ at every temperature from 25 to $400^{\circ} \mathrm{C}$. The loss increases as the frequency increase from 0.5 to $50 \mathrm{GHz}$. This phenomenon increases more so as the temperature increases as well.

\section{Antenna Design and Characterization}

The folded slot antenna was fabricated on the same substrate, and the metal conductor is the same as the CPW calibration standards ( $\mathrm{Cr} / \mathrm{Au}: 200 \AA / 1.5 \mu \mathrm{m})$. The folded slot antenna exhibits a self impedance matching technique which matches the input impedance of the antenna to the $50 \Omega$ characteristic impedance of the CPW feed line $[4,5]$. The folded slot antenna is shown in Figures $3 \mathrm{a}$ and $3 \mathrm{~b}$. The return loss (RL) of the antenna was measured at 25 and $300^{\circ} \mathrm{C}$ and is shown in Figure 4. The RL was measured using the special probe station and modified GSG probes just as with the CPW TRL calibration standards. The return loss at $25^{\circ} \mathrm{C}$ has a resonance at $3.5 \mathrm{GHz}$ and is approximately $16 \mathrm{~dB}$ in magnitude. At $300^{\circ} \mathrm{C}$ the resonance slightly shifts down in frequency to approximately 3.3 $\mathrm{GHz}$ and maintains roughly the same magnitude. This can be attributed to the increase in the effective dielectric constant as the temperature increases. Also the RL of the antenna definitely suffers from an increase in attenuation which is consistent with Figures 2 and 3.

\section{Conclusion}

The characterization of $99.6 \%$ polycrystalline alumina substrates and folded slot antennas has been presented. TRL calibrations were performed at temperatures of 25 to $400^{\circ} \mathrm{C}$ over a frequency range from 0.5 to $50 \mathrm{GHz}$. The effective dielectric constant of the CPW on alumina substrates was determined to be relatively constant at 5.4 from 25 to $200^{\circ} \mathrm{C}$ and then increased steadily to approximately 6 at $400^{\circ} \mathrm{C}$. The loss of the $\mathrm{CPW}$ lines increased as temperature and frequency increased as well noting that the increase in loss is even more profound as both the temperature and frequency increased simultaneously.

The RL of a CPW fed folded slot antenna that exhibit a self impedance matching technique has been presented. The $\mathrm{RL}$ of the folded slot antenna at $25^{\circ} \mathrm{C}$ displays a resonance at $3.5 \mathrm{GHz}$ and is approximately $16 \mathrm{~dB}$ in magnitude. At $300^{\circ} \mathrm{C}$ the resonance shifts down in frequency to approximately $3.3 \mathrm{~dB}$ and has roughly the same magnitude. However the loss of the antenna response also increases at this elevated temperature.

This work is part of the initial stages of an effort at NASA Glenn research Center to develop wireless sensors for harsh environments. This work can reduce cost, 
space to house all the hard wired connections, and reduce the weight of the overall units such as aerospace engines and allow for the placement of the wireless sensors in the engine which are not possible with hard wired sensors.

\section{Acknowledgments}

The authors would like to thank Nick Varaljay and Elizabeth McQuaid for their fabrication efforts. This work was supported by the Wireless Communications group of the Integrated Vehicle Health Management (IVHM) project.

\section{References:}

[1] Marks, R. B., “A Multiline Method of Network Analyzer Calibration”, IEEE Transaction on Microwave Theory and Techniques, Vol. 39, No. 7, Page(s): 1205 - 1215, July 1991.

[2] NIST Consortium User Guide, Nat. Inst. Standards Tech., Mar. 1991.

[3] Schwartz, Z. D., Downey, A. N. Alterovitz, S. A., and Ponchak, G. E. "HighTemperature Probe Station for use in Microwave Device Characterization Through $500^{\circ} \mathrm{C}$ ", IEEE Transaction on Instrumentation and Measurement, Vol. 54, Issue 1, Page(s) 369 - 376, Feb. 2005.

[4] Maximilian C.Scardelletti, Amjad A. Omar, and Nihad Dib, "Planar and Cylindrical CPW Fed Dual Frequecny Folded Slot Antennas." IEEE International Symposium on Antennas and Propagation, Albuquerque, NM, July 9 - 14, 2006.

[5] Amjad A. Omar, Maximilian C. Scardelletti, Zuhair M. Hejazi, and Nihad Dib, "Design and Analysis of Self-Matched Dual-Frequency Coplanar Waveguide- Fed-Slot Antennas", IEEE Antennas and Propagation Transactions, Volume 55, Issue 1, Page(s): 223 - 226, January 2007.

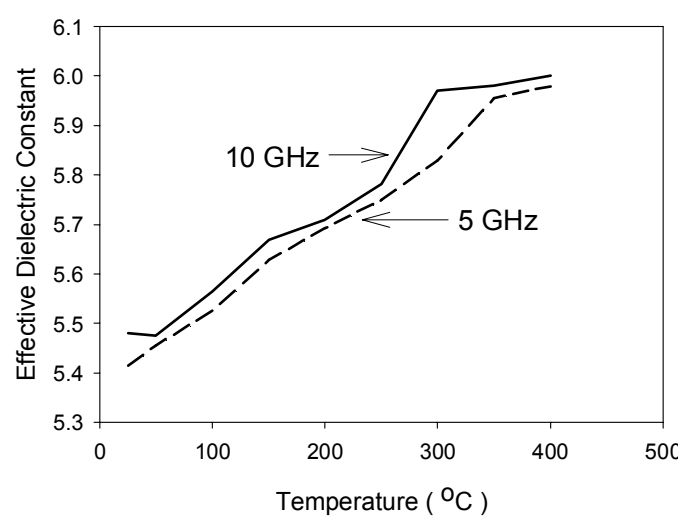

(a)

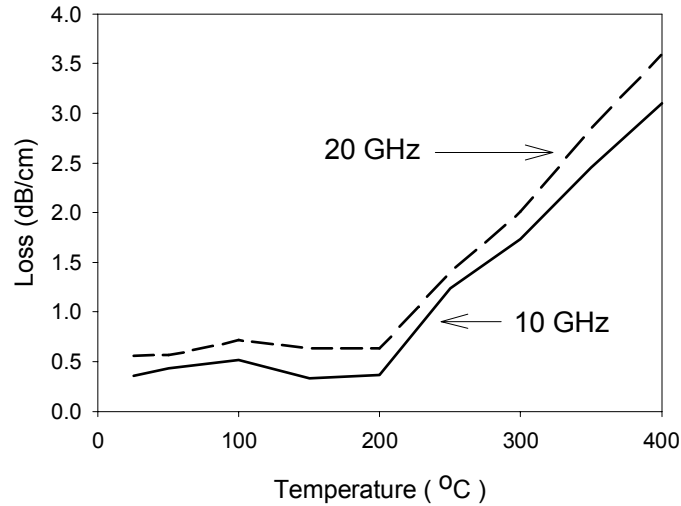

(b)

Figure 1.a) Effective dielectric vs. temperature at 5 and $10 \mathrm{GHz}$, b) Attenuation vs. temperature at 10 and $20 \mathrm{GHz}$. 


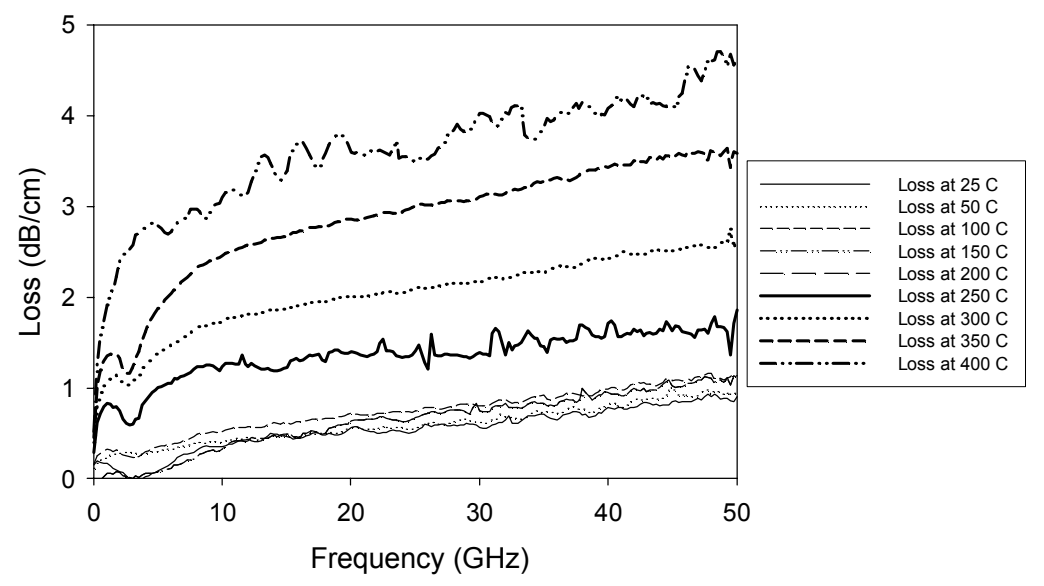

Figure 2. Loss vs. frequency as a function of temperature.

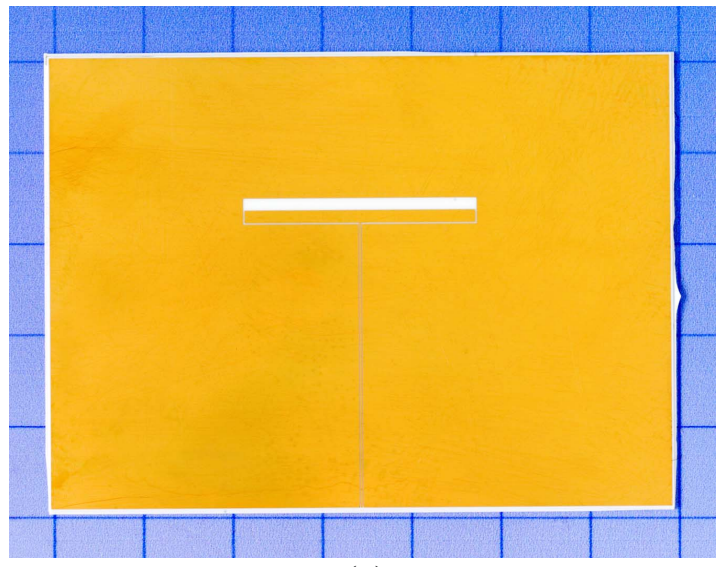

(a)

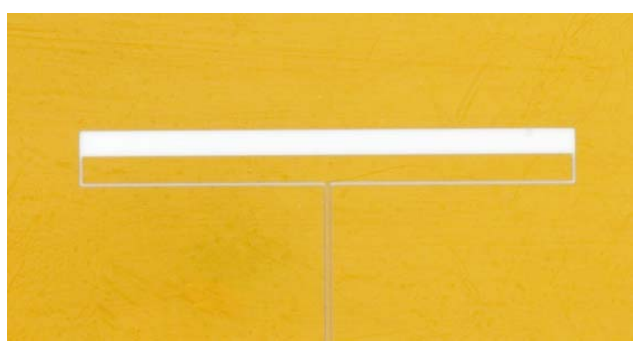

(b)

Figure 3. a) Folded slot antenna with CPW fed line b) Self impedance matching section.

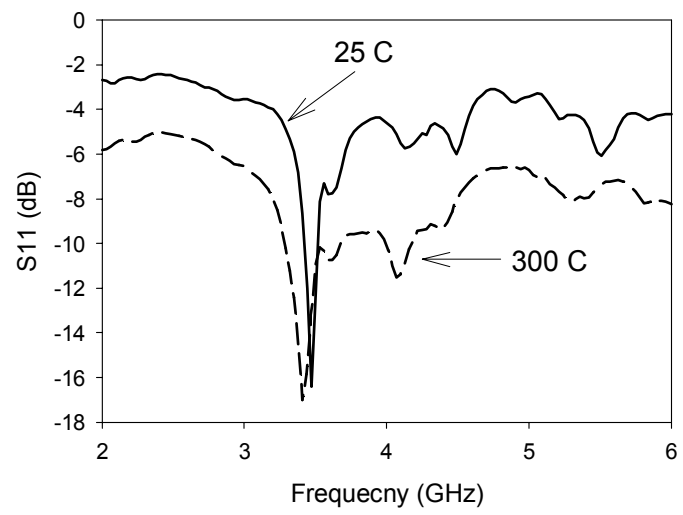

Figure 4. Return loss of folded slot antenna at 25 and $300^{\circ} \mathrm{C}$. 